\title{
Inflammatory mediators in nasal lavage, induced sputum and serum of employees with rheumatic and respiratory disorders
}

\author{
M. Roponen*, J. Kiviranta ${ }^{\#}$, M. Seuri", H. Tukiainen", R. Myllykangas-Luosujärvi ${ }^{+}$, M-R. Hirvonen*
}

Inflammatory mediators in nasal lavage, induced sputum and serum of employees with rheumatic and respiratory disorders. $M$. Roponen, J. Kiviranta, M. Seuri, $H$. Tukiainen, R. Myllykangas-Luosujärvi, M-R. Hirvonen. C ERS Journals Ltd 2001. ABSTRACT: Exposure to microbes present in mould-damaged buildings has been linked to increased frequency of various inflammatory diseases. The current study examined differences in inflammatory mediators in nasal lavage (NAL), induced sputum (IS) and serum of occupants with rheumatic or respiratory disorders and their controls, all working in the same moisture-damaged building.

Exhaled nitric oxide (NO) measurements, lung function tests, skin-prick tests and health data collection by questionnaire were performed. Concentrations of NO, interleukin (IL)-1, IL-4, IL-6 and tumour necrosis factor- $\alpha$ in NAL, IS and serum (excluding NO and IL-1) of the subjects were measured during an occupational exposure period and the vacation period without such exposure.

The concentrations of IL-4 in NAL fluid were significantly higher among all occupants during the working period (geometric mean $8.5 \mathrm{pg} \cdot \mathrm{mL}^{-1}$, range 0-206.5 $\left.\mathrm{pg} \cdot \mathrm{mL}^{-1}\right)$, as compared to that during vacation $\left(0.4 \mathrm{pg} \cdot \mathrm{mL}^{-1}\right.$, range 0-3.7 $\left.\mathrm{pg} \cdot \mathrm{mL}^{-1}\right) \quad(\mathrm{p}=\mathbf{0 . 0 0 8})$. Absence from the work environment also significantly diminished reporting of symptoms. IL-4 levels in the serum of case subjects were significantly higher than in controls. Moreover, employees with respiratory symptoms had markedly higher exhaled NO values than their controls $(p=0.028)$.

In summary, these data suggest that mediators in nasal lavage samples reflect the occupational exposure to moulds, whereas possible indicators of existing disorders are detectable in serum.

Eur Respir J 2001; 18: 542-548.

Indoor exposure to microbes is widely recognized as a potential cause of various respiratory diseases [1]. This view is supported by the authors' recent results showing an association between increased production of inflammatory markers in the nasal lavage (NAL) fluid, the high prevalence of respiratory symptoms in occupants, and chronic indoor exposure to microbes [2]. There are also case reports linking environmental exposure and a cluster of various inflammatory rheumatic diseases in a mould-damaged building [3]. Although the pathological mechanisms primarily involved in these effects remain unknown, inflammatory responses triggered by the microbial exposures in moisture-damaged buildings may be one factor responsible for these adverse health effects.

There are multiple studies demonstrating that nitric oxide (NO) and cytokines, e.g. tumour necrosis factor- $\alpha$ (TNF- $\alpha$ ), interleukin (IL)-1 $\beta$, IL-4 and IL-6, are associated with the pathogenesis of various inflammatory disorders in the airways [4, 5]. Many cytokines, including $\mathrm{TNF}-\alpha$, activate expression of inducible nitric oxide synthase (iNOS) in immunological cells, leading to the production of high amounts
*Division of Environmental Health, National Public Health Institute, Kuopio, Finland, " Dept of Respiratory Medicine, Kuopio University Hospital, Kuopio, Finland, "Kuopio Regional Institute of Occupational Health, Kuopio, Finland, ${ }^{+}$Dept of Medicine, Kuopio University Hospital, Kuopio, Finland.

Correspondence: M. Roponen, Division of Environmental Health, National Public Health Institute, P.O. Box 95, FIN-70701 Kuopio, Finland. Fax: 35817201265

\section{Keywords: Cytokines \\ nasal lavage \\ nitric oxide \\ respiratory symptoms \\ rheumatic diseases}

\section{Received: November 152000}

Accepted after revision April 142001

The study was supported by The Finnish Work Environment Fund, The Academy of Finland, Finnish Research Programme on Environmental Health and the Juho Vainio Foundation. of NO. NO is an extremely reactive radical with proinflammatory effects that may damage the surrounding cells and tissues [6].

It has recently been established that TNF- $\alpha$, IL-1 $\beta$, IL-4 and IL-6 are powerful local protein mediators in inflammation and are involved in joint destruction in autoimmune diseases such as rheumatoid arthritis (RA) [7]. TNF- $\alpha$ and IL-1 $\beta$ have a special role in the pathogenesis of autoimmune diseases by inducing production of additional inflammatory cytokines as well as synthesis and release of proteases and prostaglandin E2 [8]. IL-6 possesses many activating effects by inducing B-cell growth and differentiation, secretion of immunoglobulins and biosynthesis of acute phase proteins $[9,10]$. IL-4 may have anti-inflammatory properties in RA by inhibiting production of IL-1 and TNF- $\alpha[11]$.

The current study examined the production of inflammatory mediators in upper and lower airways and in the serum of occupants with respiratory or rheumatic diseases and their control subjects, all working in the same moisture- and mould-damaged building. Production of NO, TNF- $\alpha$, IL-1, IL-4 and 
IL-6 in NAL, induced sputum (IS) and serum (excluding NO and IL-1) was measured. In addition, measurements of exhaled NO concentrations, lung function and skin-prick tests were performed.

\section{Methods}

\section{Characterization of the exposure}

The employees working in an office building had complained of indoor air problems since 1992. Microbial samples collected in 1996 revealed moisture and mould damage in the outer wall insulation material. The worst damage was repaired in a limited area, but the indoor air complaints continued and the occupational physician noted an exceptionally high number of rheumatic inflammatory diseases. Technical, microbial and physical reinvestigations revealed that moisture and mould damage affected the whole outer layer of the building. Indoor air and outer wall insulation material samples contained microbes indicative of mould problems i.e. Aspergillus ochraceus, Aspergillus versicolor, Aspergillus fumigatus, Chaetomium spp. and Eurotium spp. Some insulation material samples contained yeast.

\section{Subjects and questionnaire}

The company employed 93 females and 15 males. Since all of the rheumatic diseases and all cases, except one, of prolonged respiratory symptoms were confined to females, the males were excluded from further studies. The mean age of the females was $46 \mathrm{yrs}$ and the mean time of employment in the building was 10 yrs. During the past $10 \mathrm{yrs}, 11$ cases of inflammatory rheumatic diseases had been diagnosed, all confirmed in the unit of rheumatology of the local university hospital.

Out of the 11 employees with rheumatic diseases, eight were still working in the building and participated in this study. Three had ankylosing spondylitis, three RA and two Sjögren's syndrome (SS). One occupant with RA also had asthma. Moreover, four employees with prolonged upper and lower respiratory symptoms were recruited. One had confirmed asthma and another allergic rhinitis. Age- and sex-matched controls ( \pm 2 yrs) without rheumatic or prolonged respiratory symptoms or diseases, working in the same building, were selected. Due to the low number of healthy employees in the older age group, only seven controls could be found for the rheumatic cases. Only one case with rheumatic disease was a current smoker (table 1).

The subjects were examined twice during the study. The first contact was during the working period to evaluate the effects of the exposure in the building. The second contact was at the end of summer vacation, to explore the effects of absence from the moisture-damaged environment. After NAL, the subjects completed a one-page questionnaire concerning their symptoms during the preceding week, i.e. symptoms in the lower airways (cough, phlegm, dyspnoea, wheezing, painful breathing), laryngeal symptoms (hoarseness, sore throat), nasal symptoms (rhinitis, bloody nasal discharge, nasal bleeding, blocked nose, maxillary sinus symptoms, sneezing, itchy nose), eye symptoms, dermal symptoms and nonspecific symptoms (fever, headache, fatigue, nausea). Use of medication and other possible sources of mould exposure were also determined. The ethical committee of Kuopio University Hospital approved the research plan.

\section{Nasal lavage}

NAL was performed as previously described [2]. Briefly, $4.5 \mathrm{~mL}$ prewarmed Hank's balanced salt solution (HBSS; Gibco, Paisley, UK) $\left(37^{\circ} \mathrm{C}\right)$ was instilled into the nostril through a heat softened catheter. The cartilaginous bridge of the nose was vibrated with a neonatal percussor (Neo-Cussor ${ }^{\mathrm{TM}}$, General Physiotherapy Inc., MO, USA), and the fluid was refluxed three times. The procedure was then repeated on the opposite nostril. The sample was centrifuged $(425 \times g$ for $10 \mathrm{~min})$, the cells were resuspended in $2 \mathrm{~mL}$ of the supernatant, and the rest of the cell-free supernatant was removed and frozen. The remaining cell suspension was incubated for $24 \mathrm{~h}$ at $37^{\circ} \mathrm{C}$ and then centrifuged $(425 \times g$ for $10 \mathrm{~min})$. The supernatant and cells were frozen at $-70^{\circ} \mathrm{C}$.

Table 1. - Subject characteristics

\begin{tabular}{|c|c|c|c|c|}
\hline & \multicolumn{2}{|c|}{ Respiratory group } & \multicolumn{2}{|c|}{ Rheumatic group } \\
\hline & Cases & Controls & Cases & Controls \\
\hline Number of subjects ${ }^{\#}$ & 4 & 4 & 8 & 7 \\
\hline Age yrs mean (range) & $49(43-52)$ & $49(43-52)$ & $51(44-57)$ & $51(43-59)$ \\
\hline Current smokers & 0 & 0 & 1 & 0 \\
\hline \multicolumn{5}{|l|}{ Positive SPT reactions } \\
\hline Basic series & 2 & 0 & 2 & 0 \\
\hline Moulds & 0 & 0 & 0 & 0 \\
\hline Storage mites & 1 & 2 & 4 & 0 \\
\hline Total number of atopics & 2 & 2 & 4 & 0 \\
\hline
\end{tabular}

SPT: skin-prick test. ${ }^{\#}$ : all females; ${ }^{\top}$ : mean wheal diameter $\geqslant 3 \mathrm{~mm}$ in SPT to at least one common allergen. 


\section{Induced sputum collection}

IS collection was performed as described earlier [12]. Briefly, the sputum was induced with inhalation of ultrasonically nebulized hypertonic $(3 \%)$ saline. The sputum plugs originating from the lower respiratory tract were separated and the remainder was resuspended in HBSS (final volume $5 \mathrm{~mL}$ ), centrifuged $(425 \times g$ for $10 \mathrm{~min})$ and processed like NAL samples. The collected plugs were mixed with dithiotreitol (Sputolysin, Calbiochem corporation, San Diego, CA, USA) and Dulbeccos phosphate-buffered saline (Gibco, Paisley, UK), filtered and centrifuged $(790 \times g$ for $10 \mathrm{~min})$. From the cell pellet, the cell viability was estimated by trypan blue exclusion method. Concentration of eosinophil cationic protein (ECP) in the sputum supernatant was measured by radioimmunossay (Pharmacia \& Upjohn, Uppsala, Sweden).

\section{Cytospin}

Cytocentrifuge preparation was made from $100 \mu \mathrm{L}$ (NAL) and $75 \mu \mathrm{L}$ (IS) of cell suspension. Mucus was broken using $10 \%$ sputolysin and the solution was centrifuged $(32 \times g, 10 \mathrm{~min}$; Megafuge, Heraus Instruments, Germany). The slides were fixed using methanol and stained with May-Grunwald-Giemsa [13] staining for the cell differential counts.

\section{Nitric oxide analysis}

NO in the supernatant was assayed by the Griess reaction as the stable NO oxidation product nitrite [14], as described earlier [15]. Expression of iNOS in the cells of NAL was determined with Western blot analysis [15] with minor modifications.

\section{Cytokine analysis}

Cytokines from IS and NAL supernatants and serum were analysed from IS and NAL supernatants and serum by using DuoSeT human TNF- $\alpha$, IL-1, IL-4 and IL-6 enzyme-linked immunosorbent assay (ELISA) kits obtained from R\&D Systems (Minneapolis, MN, USA). Assays were performed as recommended by the manufacturer.

\section{Measurement of exhaled nitric oxide}

Exhaled NO was measured by a chemiluminescence analyser (Sievers Model 280 NOA, Sievers Instruments Inc., Boulder, CO, USA) according to European Respiratory Society guidelines [16], as described earlier [12]. Briefly, subjects performed a slow vital capacity manoeuvre for $30 \mathrm{~s}$ against a fixed expiratory resistance. The relative standard deviation between three exhaled samples was expected to be $<10 \%$. The detection limit for NO was 1 parts per billion (ppb).

\section{Lung function tests}

Spirometry and measurement of pulmonary diffusion capacity were performed according to American Thoracic Society guidelines $[17,18]$. Seven subjects with rheumatic disease and two with respiratory symptoms and their controls, conducted the followup by recording their peak expiratory flow (PEF) values for 2 weeks.

\section{Skin-prick tests}

Atopic status of the subjects was evaluated using ALK skin-prick test system (ALK Laboratories, Denmark) with 14 common environmental allergens (house dust mite (Dermatophagoides farinae and $D$. pteronyssimus), grass pollen, birch, alder, meadow grass, timothy, mugwort, dandelion, horse, dog, cat, cow, and natural rubber latex), three storage mites (Lepidoglyfus destructor, Acarus siro and Tyrophagus putrescentiae) and 13 moulds (Altenaria alternata, Cladosporium herbarum, Aspergillus fumigatus, $A$. versicolor, Aureobasidium pullulans, Botrytis cinerea, Chaetomium globusum, Geotrichium candidum, Mucor racemosus, Penicillium brevicompactum, P. expansum, Phoma herbarum and Trichoderma viride). Histamine hydrochloride $\left(10 \mathrm{mg} \cdot \mathrm{mL}^{-1}\right)$ and ALK allergen diluent mediums were used as positive and negative controls. Atopy was defined as at least one positive reaction with a diameter of $\geqslant 3 \mathrm{~mm}$ and twice the size of negative controls when they had given a positive reaction.

\section{Blood samples}

Blood samples for the cytokine analysis, immunoglobulin (Ig)-E measurements and ECP tests were drawn at the same time with NAL. IgE and ECP values were analysed in Helsinki Skin and Allergy Hospital with commercial radioimmunoassays (Pharmacia \& Upjohn, Uppsala, Sweden).

\section{Statistical analysis}

The Wilcoxon signed-rank test was used to compare each case subject to their age-matched control and to evaluate individual differences between working time and vacation time. In the comparison of different groups of subjects, nonparametric Kruskall-Wallis and Mann-Whitney tests were used.

\section{Results}

\section{Skin-prick tests}

Eight subjects out of 23 had positive skin-prick reaction induced by at least one of the tested allergens. Two of them were controls and six case subjects (table 1). Two subjects with rheumatic diseases and two with prolonged respiratory symptoms gave 
Table 2. - Symptoms reported by the subjects at work and during the vacation

\begin{tabular}{lccccccc}
\hline Symptom & Subjects n & $\begin{array}{c}\text { Lower } \\
\text { airways }\end{array}$ & $\begin{array}{c}\text { Laryngeal } \\
\text { symptoms }\end{array}$ & $\begin{array}{c}\text { Nasal } \\
\text { symptoms }\end{array}$ & $\begin{array}{c}\text { Eye } \\
\text { symptoms }\end{array}$ & $\begin{array}{c}\text { Skin } \\
\text { symptoms }\end{array}$ & $\begin{array}{c}\text { Nonspecific } \\
\text { symptoms }\end{array}$ \\
\hline Work & 22 & $16^{*}$ & 13 & 19 & $14^{* *}$ & $5^{*}$ & $10^{* *}$ \\
Vacation & 23 & 9 & 7 & 13 & 3 & 0 & 2 \\
\hline
\end{tabular}

Data are presented as number of workers reporting symptoms. *: $\mathrm{p}<0.05 ;{ }^{* *}: \mathrm{p}<0.01$, determined using Mann-Whitney test.

positive reactions in the basic series. Four subjects with rheumatic diseases had a positive reaction for $T$. putrescentiae and two of them also had a reaction for $A$. siro. In the respiratory group, one case and two controls had positive reactions for the tested storage mites. In all, seven of the 23 subjects had positive reaction for $T$. putrescentiae.

\section{Symptoms}

The reported symptoms were significantly more frequent during the exposure period than at the end of nonexposure period (table 2). There were no differences in the reporting of symptoms between cases and their controls or between subjects with rheumatic and respiratory disorders. Atopic subjects reported significantly more nasal symptoms $(\mathrm{p}=0.012)$ and symptoms in the lower airways $(p=0.013)$ during the working period than subjects with no atopic tendency. Absence from the building significantly decreased complaints of nasal and eye symptoms and symptoms in the lower airways in the atopic subjects, whereas in the nonatopic individuals only the frequency of eye symptoms was significantly decreased.

Nitric oxide production in nasal lavage and induced sputum and expression of inducible nitric oxide synthase

Production of NO, assessed as nitrite levels in NAL, was slightly increased during the working period (geometric mean $1.6 \mu \mathrm{M}$, range $0-11.9 \mu \mathrm{M}$ ) compared to the value during the vacation $(1.2 \mu \mathrm{M}$, range
$0-5.3 \mu \mathrm{M})$. There were no differences in the nitrite levels in the NAL fluid between cases and their references or between subjects with rheumatic and respiratory problems. Nitrite concentrations in IS were only slightly higher during the occupational exposure period $(2.9 \mu \mathrm{M}$, range $0.8-30.4 \mu \mathrm{M})$ than those from vacation period $(2.4 \mu \mathrm{M}$, range 0.4 $6.9 \mu \mathrm{M})$. An atopic tendency had no effect on the nitrite levels in NAL or IS. Consistent with the highest nitrite concentrations in NAL and IS, the expression of iNOS was detectable in cells (data not shown).

\section{Exhaled nitric oxide}

Exhaled NO values ranged 5.3-77.2 ppb (mean $19.3 \pm 13.4 \mathrm{ppb}$ ). Rheumatic subjects did not differ from their controls during the working or vacation period, but the subjects with a history of respiratory symptoms had significantly higher exhaled NO values than their controls ( 10.7 and $5.6 \mathrm{ppb}$, respectively) $(\mathrm{p}=0.028)$. However, there was no difference between values at work and on vacation. Atopic tendency had no effect on exhaled NO.

\section{Cytokine concentrations in nasal lavage and induced sputum}

Concentrations of IL-1, IL-4, IL- 6 and TNF- $\alpha$ in NAL were increased during the working period, compared to those taken in the vacation (fig. 1). However, only the difference in the concentrations of IL-4 was statistically significant (geometric mean $8.5 \mathrm{pg} \cdot \mathrm{mL}^{-1}$, range $0-206.5 \mathrm{pg} \cdot \mathrm{mL}^{-1}$ versus geometric
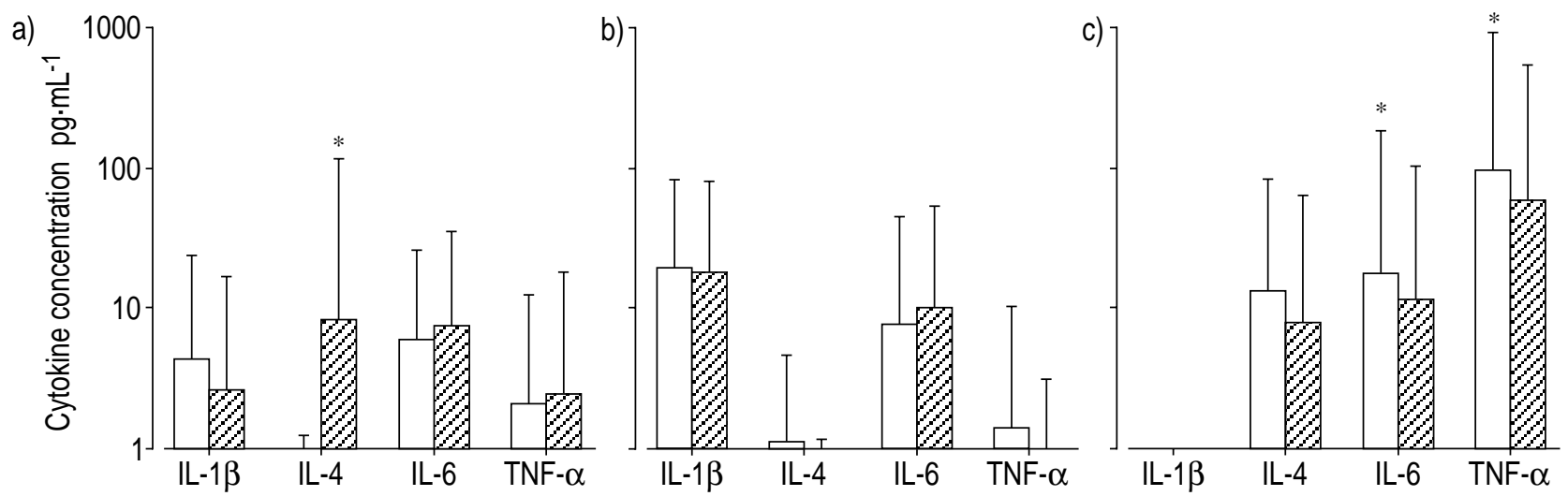

Fig. 1.-Geometric mean concentrations of interleukin (IL)-1, IL-4, IL-6 and tumour necrosis factor- $\alpha$ (TNF- $\alpha$ ) in a) nasal lavage fluid, b) induced sputum, and c) serum of the office workers at work $(\mathbb{C})$ and during vacation $(\square)$. IL-1 $\beta$ was not measured in the serum. The Wilcoxon signed-rank test was performed. *: indicates significant difference $(\mathrm{p}<0.05)$. 
mean $0.4 \mathrm{pg} \cdot \mathrm{mL}^{-1}$, range $\left.0-3.7 \mathrm{pg} \cdot \mathrm{mL}^{-1}\right)(\mathrm{p}=0.008)$, this being most evident among the symptomatic employees. There were no significant differences in the NAL cytokine levels between the case subjects and their references (fig. 2) or between subjects with rheumatic and respiratory diseases. Interestingly, the concentrations of IL-4 in NAL were only significantly increased in the nonatopic subjects during the working period, compared to those during vacation $(\mathrm{p}=0.028)$. Otherwise, there were no differences between atopic and nonatopic subjects in the studied biomarkers in NAL or IS.

All the measured cytokines were detectable in the IS samples of studied employees (IL-1 geometric mean of all the measurements $18.1 \mathrm{pg} \cdot \mathrm{mL}^{-1}$, range $0-123.3 \mathrm{pg} \cdot \mathrm{mL}^{-1}$; IL-4 $0.8 \mathrm{pg} \cdot \mathrm{mL}^{-1}, 0-56.9 \mathrm{pg} \cdot \mathrm{mL}^{-1}$; IL-6 $8.3 \mathrm{pg} \cdot \mathrm{mL}^{-1}, 0-331.0 \mathrm{pg} \cdot \mathrm{mL}^{-1}$; TNF- $\alpha 1.1 \mathrm{pg} \cdot \mathrm{mL}^{-1}$, $\left.0-1,276.3 \mathrm{pg} \cdot \mathrm{mL}^{-1}\right)$. In contrast to NAL, there were no significant differences in the IS cytokine levels between working and vacation periods (fig. 1), between the cases and their controls (fig. 2) or between subjects with rheumatic and respiratory disorders.

\section{Serum cytokines}

Serum TNF- $\alpha(\mathrm{p}=0.049)$ and IL-6 $(\mathrm{p}=0.001)$ concentrations were significantly increased during vacation, as compared to working period (fig. 1). The difference was most obvious among rheumatic employees. Concentrations of all of the studied cytokines were increased in the serum of the cases, as compared to the controls (fig. 2). However, only the increase in the IL-4 concentration was statistically significant $(p=0.049)$. There were no differences between atopic and nonatopic subjects in studied serum cytokine concentrations.

\section{Cell differential count}

Neutrophilic cells dominated NAL and IS cell profiles. There were no differences in the proportion of lymphocytes, neutrophils and eosinophils in the
NAL or IS between the working period and vacation, between cases and controls or between subjects with rheumatic and respiratory disorders. Atopic subjects had a significantly higher proportion of neutrophils $(\mathrm{p}=0.003)$ and eosinophils $(\mathrm{p}=0.025)$ in NAL during the vacation than nonatopic subjects. In the IS, subjects with prolonged respiratory symptoms had a significantly higher proportion of macrophages $(2.2 \%)$ than their controls $(1.5 \%)(\mathrm{p}=0.021)$. There were no differences in the sputum ECP values between different groups or between working and vacation periods.

\section{Lung functions}

In spirometry, the forced expiratory volume in one second (FEV1) ranged 80-119\% (mean 94\%) of the predicted value in all the studied subjects except the rheumatic case with asthma $(50 \%)$. There were no significant differences in spirometry and pulmonary diffusion capacity between work and vacation, between the subjects with rheumatic and respiratory disorders or between cases and controls. Total lung diffusion capacity ranged $80-136 \%$ (mean $110 \%$ ) of the predicted value. The mean percentage of the PEF variation during the working and off-work days was $12.5 \%$ and $13.9 \%$, respectively, the difference being statistically nonsignificant. No work related PEF falls were seen and the greatest daily PEF differences were seen on days out of work.

\section{Blood samples}

Serum IgE and ECP values were low (2.116.6 IU $\cdot \mathrm{L}^{-1}$ and $9.4-84.7 \mathrm{IU} \cdot \mathrm{L}^{-1}$, respectively) in all of the studied subjects.

\section{Discussion}

In Finland, $\sim 1 \%$ of the whole population is taking reimbursed medication for some inflammatory rheumatic disease [19]. However, the relative risk of
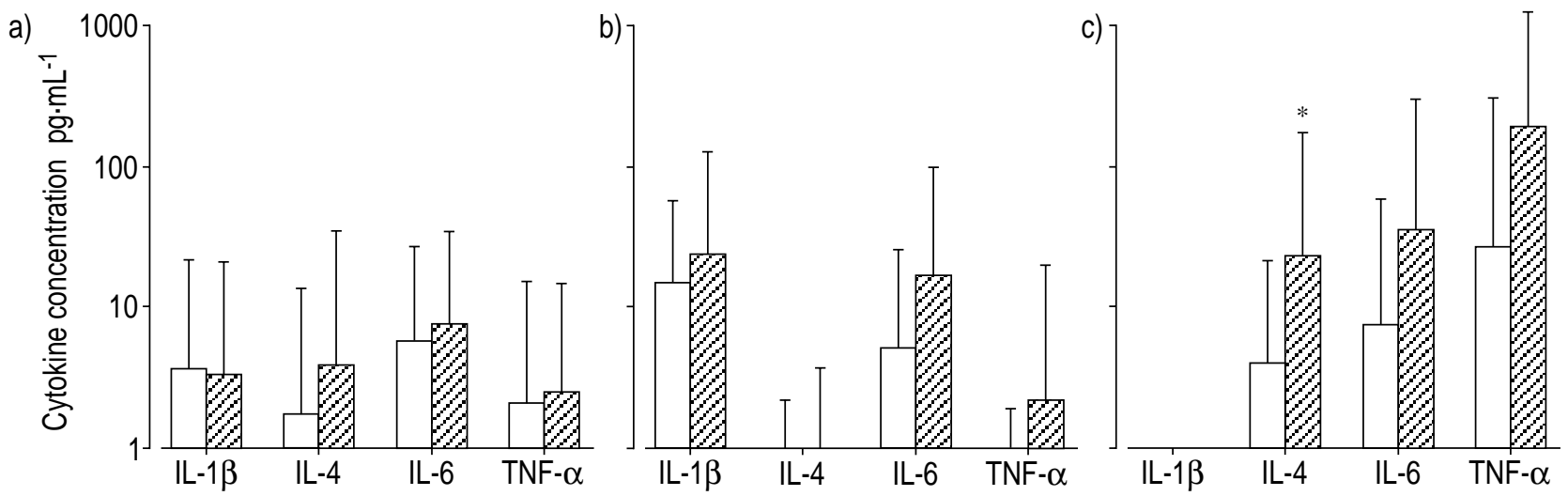

Fig. 2.-Geometric mean concentrations of interleukin (IL)-1, IL-4, IL-6 and tumour necrosis factor- $\alpha$ (TNF- $\alpha$ ) in a) the nasal lavage fluid, b) induced sputum, and c) serum of the symptomatic $(\mathbb{Z})$ and nonsymptomatic $(\square)$ employees (pooled data from vacation and work). IL-1 $\beta$ was not measured in the serum. The Wilcoxon signed-rank test was performed. *: indicates significant difference, as compared with controls $(\mathrm{p}<0.05)$. 
inflammatory rheumatic diseases during 1990-1996 was 12.7 (95\% confidence interval 5.5-27.6) in the occupants of the studied office building [3], and since then another four new cases have been diagnosed. In the present study, employees with prolonged respiratory symptoms or rheumatic disease and their reference subjects reported the same kind of symptoms, as observed earlier in an epidemiological study of people living or working in moisture-damaged buildings [1]. They did, however, report more skin and eye symptoms than employees of a school with a mouldy building in a previous study [2]. During the vacation, all of the reported symptoms diminished, indicating that they were related to workplace exposure.

The prevalence of positive skin-prick tests for storage-mite allergens was unusually high in these employees. This is of special interest since atopy to different storage mites has been commonly associated with the agricultural environment [20], whereas house dust mites are a known risk factor of asthma in urban dwellings [21]. The present observation, suggesting a link between storage mites and rheumatic and respiratory diseases, needs to be clarified in future studies.

The present data show that production of IL-4 in NAL, reflecting upper airway responses, was significantly elevated during the working period in all of the studied occupants, as compared to the values during the vacation. The difference was most apparent among the nonatopic subjects. The more stable IL-4 production among the atopic individuals may be due to atopy-related sensitivity to different environmental allergens and irritants as a whole. Moreover, all except two of the atopic subjects were taking medication for either rheumatic or respiratory diseases, which may have influenced the level of the production of the cytokines in this group. These results support earlier findings suggesting that occupational exposure in a mould-damaged building leads to increased production of inflammatory mediators in the upper airways of exposed occupants [2].

Systemic IL-4 levels in the serum were higher in the samples of the cases than in their controls. This observation is in-line with reports indicating a significant role of IL-4 in the pathogenesis of both respiratory and rheumatic diseases. Elevated IL-4 concentrations have been detected in the serum of asthmatic patients [22] and there are reports showing that stimulated peripheral blood mononuclear cells from atopic children with asthma produce more IL-4 than cells from nonatopic controls [23]. Furthermore, IL-4 downregulates Th1-mediated inflammatory responses and it may have immunosuppressive or even preventive potential in autoimmune diseases [11]. The low incidence of Th2-type disorders, such as atopy, in RA patients supports this view [24]. These phenomena are thought to result from the opposite immunological cytokine profiles in Th1 and Th2 mediated diseases, which may lead to antagonist effects. Interestingly, IL- 6 and TNF- $\alpha$ concentrations in the serum samples were higher during vacation than the working period, the difference being most apparent in the rheumatic employees. This may be due to the possible immunosuppressive potential of mycotoxins originating from the microbes in the moisturedamaged buildings [25]. Moreover, the decrement in the production of pro-inflammatory cytokines during the working period may be related to increased production of IL-4 caused by occupational exposure. However, it is not clear if endogenous production of IL-4 is sufficient to control these disease processes. Continual cell activation may exhaust the ability of IL-4 to inhibit the bioactivity of proinflammatory cytokines.

Exhaled NO values were significantly higher only among the subjects with prolonged respiratory symptoms compared to their controls. The difference was equal during working and vacation periods. This finding is in concordance with earlier reports showing an increase in the exhaled NO concentration in respiratory disorders, such as asthma, upper respiratory tract infections and asthma-like symptoms [26-28]. Elevated exhaled nitric oxide levels have also been demonstrated in patients with SS [29]. This phenomenon, however, was not detectable in the present study, which included only two cases with SS. Moreover, no differences between case and control groups were seen in NO levels of NAL and IS samples, indicated as nitrite concentrations, in spirometry, in pulmonary diffusion capacity or in PEF follow-up. Previously it has been shown that formaldehyde exposure at home increases exhaled NO levels in healthy children at concentrations that have no effect on lung function [30]. This indicates that inflammatory reactions in the airways can be detected at lower exposure levels than changes in pulmonary functions.

The present data reveal that measurement of inflammatory mediators in nasal lavage and induced sputum can be used to assess the exposure to microbes in a moisture-damaged indoor environment, whereas possible indicators of existing disorders may be detectable in the serum samples.

\footnotetext{
Acknowledgements. The authors wish to thank the office personnel for participation in the study. L. Heikkinen, H. Martikainen and R. Tukiainen are acknowledged for their excellent technical assistance, M. Vahteristo, for help in statistical analyses and E. MacDonald for reading and commenting on the manuscript.
}

\section{References}

1. Husman T. Health effects of indoor-air microorganisms. Scand J Work Environ Health 1996; 22: 5-13.

2. Hirvonen M-R, Ruotsalainen M, Roponen M, et al. Nitric oxide and proinflammatory cytokines in nasal lavage fluid associated with symptoms and exposure to moldy building microbes. Am J Respir Crit Care Med 1999; 160: 1943-1946.

3. Seuri M, Korhonen R, Husman T, MyllykangasLuosujärvi R, Aho K. A cluster of inflammatory diseases in a damp office. Scand J Rheumatol 1998; 27 : 246. 
4. Broide DH, Lotz M, Cuomo AJ, Coburn DA, Federman EC, Wasserman SI. Cytokines in symptomatic asthma airways. J Allergy Clin Immunol 1992; 89: 958-967.

5. Bradding $\mathrm{P}$, Roberts JA, Britten $\mathrm{KM}$, et al. Interleukin-4, -5 , and -6 and tumor necrosis factor-alpha in normal and asthmatic airways: evidence for the human mast cell as a source of these cytokines. $\mathrm{Am}$ J Respir Cell Mol Biol 1994; 10: 471-480.

6. Clancy RM, Abramson SB. Nitric oxide: A novel mediator of inflammation. Proc Soc Exp Biol Med 1995; 210: 93-101.

7. Breedveld FC. Future trends in the treatment of rheumatoid arthritis: cytokine targets. Rheumatology 1999; 38: Suppl. 2, 11-13.

8. Fox DA. Cytokine blockade as a new strategy to treat rheumatoid arthritis. Arch Intern Med 2000; 160: 437 444.

9. Barton BE. IL-6: Insights into novel biological activities. Clin Immunol Immunopathol 1997; 85: 16-20.

10. Hirano T, Akira S, Taga T, Kishimoto T. Biological and clinical aspects of interleukin-6. Immunol Today 1990; 11: 443-449.

11. Miossec P, Briolay J, Dechanet J, Wijdenes $\mathrm{J}$, Martinez-Valdez H, Banchereau J. Inhibition of the production of proinflammatory cytokines and immunoglobulins by interleukin-4 in an ex vivo model of rheumatoid synovitis. Arthritis Rheum 1992; 35: 874 883.

12. Purokivi M, Randell J, Hirvonen M-R, Tukiainen H. Reproducibility of measurements of exhaled NO, and cell count and cytokine concentrations in induced sputum. Eur Respir J 2000; 16: 242-246.

13. Prat J, Xaubet A, Mullol J. Immunocytologic analysis of nasal cells obtained by nasal lavage: a comparative study with a standard method of cell identification. Allergy 1993; 48: 587-591.

14. Green LC, Wagner DA, Glogowski J, Skipper PL, Wishnok JS, Tannenbaum SR. Analysis of nitrate, nitrite and $\left[{ }^{15} \mathrm{~N}\right]$ nitrate in biological fluids. Anal Biochem 1982; 126: 131-138.

15. Hirvonen M-R, Nevalainen A, Makkonen N, Mönkkönen J, Savolainen K. Induced production of nitric oxide, tumor necrosis factor, and interleukin-6 in RAW 264.7 macrophages by Streptomycetes from indoor air of moldy houses. Arch Environ Health 1997; 6: 426-432.

16. Kharitonov S, Alving K, Barnes PJ. Exhaled and nasal nitric oxide measurements: recommendations. Eur Respir J 1997; 10: 1683-1693.

17. American Thoracic Society. Standardization of spirometry, 1994 Update. Am Respir Crit Care Med 1995; 152: 1107-1136.
18. American Thoracic Society. Recommendations for DLCO. Am J Respir Crit Care Med 1996; 154: 263.

19. Kaipiainen-Seppänen O. Incidence of chronic inflammatory rheumatic diseases in Finland during 19751990. Kuopio University Publications D. Medical Sciences 1997; 117: 1-98.

20. Hanhela R. The effect of working conditions on development of occupational asthma in dairy farming (dissertation, in Finnish with English abstract). Finland, Espoo, Farmers' Social Insurance Institution Publications, 1999.

21. Marks GB. House dust mite exposure as a risk factor for asthma: benefits of avoidance. Allergy 1998; 53: Suppl. 48, 108-114.

22. Matsumoto K, Taki F, Miura M, Matsuzaki M, Takagi K. Serum levels of soluble IL-2R, IL-4, and soluble Fc epsilon RII in adult bronchial asthma. Chest 1994; 105: 681-686.

23. Tang ML, Coleman J, Kemp AS. Interleukin-4 and interferon-gamma production in atopic and nonatopic children with asthma. Clin Exp Allergy 1995; 25: 515-521.

24. Hilliquin P, Allanore Y, Coste J, Renoux M, Kahan A, Menkès CJ. Reduced incidence and prevalence of atopy in rheumatoid arthritis. Results of a casecontrol study. Rheumatol 2000; 39: 1020-1026.

25. Robbins CA, Swenson LJ, Nealley ML, Gots RE, Kelman BJ. Health effects of mycotoxins in indoor air: a critical review. Appl Occup Environ Hyg 2000; 15: 773-784.

26. Kharitonov SA, Yates D, Robbins RA, LoganSinclair R, Shinebourne EA, Barnes PJ. Increased nitric oxide in exhaled air of asthmatic patients. Lancet 1994; 343: 133-135.

27. Kharitonov SA, Yates D, Barnes PJ. Increased nitric oxide in exhaled air of normal human subjects with upper respiratory tract infections. Eur Respir J 1995; 8: 295-297.

28. Sovijärvi ARA, Saarinen A, Helin T. Exhaled nitric oxide is increased in patients with asthmatic symptoms not fulfilling the functional criteria of asthma. Clin Physiol 1998; 18: 264.

29. Ludviksdottir D, Janson C, Högman $\mathrm{M}$, et al. Increased nitric oxide in expired air in patients with Sjogren's syndrome. Eur Respir J 1999; 13: 739-743.

30. Franklin PJ, Dingle PW, Stick SM. Formaldehyde exposure in homes is associated with increased levels of exhaled nitric oxide in healthy children. In: Seppänen O, Säteri J, eds. Proceedings of Healthy Buildings 2000. Vol. 1 (Exposure, human responses and building investigations) Helsinki, Finland, SIY. Indoor Information, 2000; pp. 65-70. 